\title{
Hypothyroidism in Conakry: Epidemiological, Clinical and Therapeutic Aspects
}

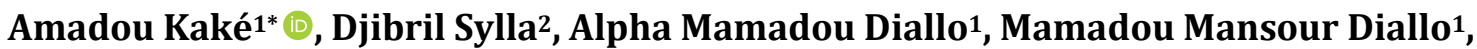
Lanciné Kourouma1', Amadou Diango', Mamadou Alpha Diallo', Elhadj Zainoul Bah', Mamadou Cherif Diallo1, Kadija Dieng1, Mody Abdoulaye Barry', Naby Moussa Baldé1
\end{abstract}

${ }^{1}$ Department of Endocrinology and Metabolic Diseases, Donka University Hospital, Conakry, Guinea

${ }^{2}$ Department of Internal Medicine, Donka University Hospital, Conakry, Guinea

Email: *amadoukake@gmail.com

How to cite this paper: Kaké, A., Sylla, D., Diallo, A.M., Diallo, M.M., Kourouma, L., Diango, A., Diallo, M.A., Bah, E.Z., Diallo, M.C., Dieng, K., Barry, M.A. and Baldé, N.M. (2022) Hypothyroidism in Conakry: Epidemiological, Clinical and Therapeutic Aspects. Open Journal of Internal Medicine, 12, 38-45.

https://doi.org/10.4236/ojim.2022.121005

Received: December 30, 2021

Accepted: February 14, 2022

Published: February 17, 2022

Copyright () 2022 by author(s) and Scientific Research Publishing Inc. This work is licensed under the Creative Commons Attribution International License (CC BY 4.0).

http://creativecommons.org/licenses/by/4.0/

\begin{abstract}
Hypothyroidism is a frequent endocrine disorder that can occur at any age and predominantly affects women. The etiologies are diverse and may vary according to the geographical and socio-demographic context. The objective of our work was to describe the epidemiological, clinical and therapeutic characteristics of hypothyroidism in Conakry, Guinea. Materials and Method: This was a descriptive study with prospective data collection, over the period from December 2016 to May 2021. It focused on patients seen at the endocrinology consultation of Conakry University Hospital. Epidemiological, clinical, etiological, therapeutic, and evolutionary variables of patients diagnosed or followed-up for hypothyroidism were collected and analyzed. The diagnosis of hypothyroidism was defined by elevated TSH and/or decreased FT4/FT3. Results: Out of a total of 290 patients who consulted for thyroid pathology, hypothyroidism concerned 49 patients, i.e., a frequency of $14 \%$. Women were the most affected with a sex ratio of 0.13 . The mean age of patients was $48.65 \pm 19.93$ years with extremes of 2 years and 80 years. Hypo-metabolic syndrome was the main clinical sign and was manifested mainly by constipation found in $48.89 \%$ of cases. TSH was elevated in all cases with a mean level of $24.56 \pm 14.17$ $\mathrm{mIU} / \mathrm{ml}$. Hypertension was the most frequently associated pathology (57\%). Three etiological groups of hypothyroidisms were found. These were thyroidectomy in $42.85 \%$ of cases, thyroiditis in $34.69 \%$ of cases and post synthetic antithyroid hypothyroidism. All patients were treated with L-thyroxin, with a favorable clinical course. Follow-up was regular in 16 patients (32.65\%). Conclusion: Hypothyroidism is common in this population, and primarily affects women. Thyroid surgery was the main cause of hypothyroidism in this work.
\end{abstract}

\section{Keywords}

Hypothyroidism, Goiter, Hashimoto, Guinea 


\section{Introduction}

Hypothyroidism is the clinical and biological expression of thyroid hormone deficiency. It can be either of primary or secondary origin and responsible for hypo-metabolism, whatever the etiology [1]. It is a predominantly female condition and its prevalence in the general population varies between $0.1 \%$ and $2 \%$ [1]. In the United States, the prevalence of overt hypothyroidism in the general population was $0.3 \%$ and the prevalence of subclinical hypothyroidism was $4.3 \%$ in $2007[1]$.

In sub-Saharan Africa, hypothyroidism is dominated by iodine deficiency and is associated with endemic goiter, which has been decreasing significantly since the introduction of salt iodization policies in the 1990s [2]. In two studies conducted in Niger, thyroidectomy was the main etiology of hypothyroidism, followed by autoimmune causes [2] [3].

In Guinea, there are no specific published data on hypothyroidism. In a study of thyroid pathology at the University Hospital of Conakry, the proportion of hypothyroidism at the endocrinology consultation of the University Hospital of Conakry was $11 \%$ in 2020 [4].

The objective of this work was to describe the epidemiological, clinical and therapeutic characteristics of hypothyroidism followed-up at the University Hospital of Conakry, Guinea.

\section{Patients and Methods}

This was a descriptive study with prospective data collection conducted from December 1, 2016 to May 31, 2021. All patients received at the endocrinology consultation of the University Hospital of Conakry for thyroid gland pathology were included. The patients had undergone an interrogation with collection of data on age, sex, occupation, residence, family and personal history. All patients had undergone a systematic clinical examination looking for signs of hypo metabolism and myxedematous syndrome.

Complementary explorations had been proposed according to the clinical context. It was a hormonal exploration with dosage of ultra-sensitive Thyreostimuline (TSHus), free triiodothyronine (FT3), and free tetraiodothyronine (FT4). An inflammatory workup including sedimentation rate (ESR), C-reactive protein (CRP), and a blood count was performed.

An immunological workup with anti thyroperoxidase (TPO) and anti-thyroglobulin (TG) antibodies was performed when applicable.

Thyroid ultrasound with determination of the TIRADS (Thyroid Imaging Reporting and Data System) classification [5], and fine needle aspiration biopsy in case of thyroid nodules were proposed.

Peripheral hypothyroidism was defined by a decrease in thyroid hormone levels (free T3 and free T4) and an increase in TSHus.

Hashimoto's thyroiditis was retained in the presence of a goiter, positivity of anti-TPO or anti-TG antibodies. 
The study was conducted in accordance with the Helsinki declaration. Data were collected and analyzed anonymously using EPI Info 7.2.2.6 and SPSS version 22.0 software.

\section{Results}

\section{Epidemiological characteristics (see Table 1)}

Of a total of 290 patients seen at the consultation for thyroid pathology, 49 patients had hypothyroidism, a frequency of $14 \%$. The mean age of our patients was $48.65 \pm 19.93$ years with extremes ranging from 2 to 80 years; the most represented age group was 52 - 61 years, i.e., $22.44 \%$. The female sex was predominant in our study with $88 \%$ or a sex ratio of 0.13 .

A total of $63 \%$ of the patients resided in Conakry, and $37 \%$ came from other regions of Guinea. Housewives were the most affected socio-professional category $(40.81 \%)$, followed by civil servants in $28.57 \%$ of cases and patients working in the informal sector in $28.6 \%$ of cases.

Clinical characteristics (see Table 2)

The hypo-metabolic syndrome was dominated by constipation in $44.89 \%$ (22 cases), physical asthenia in $46.67 \%$ (21 cases), chilliness in $30.61 \%$ (15 cases). The syndrome of cutaneous and subcutaneous infiltration was found and was manifested by weight gain in $30.61 \%$ (15 cases) and a hoarseness of voice in

Table 1. Distribution of socio-demographic characteristics of patients.

\begin{tabular}{|c|c|c|}
\hline Socio-demographic characteristics & $\begin{array}{l}\text { Number } \\
(n=49)\end{array}$ & $\begin{array}{c}\text { Percentage } \\
(\%)\end{array}$ \\
\hline Mean age & $48.65 \pm 19.93$ years & (2 - 80 years) \\
\hline \multicolumn{3}{|l|}{ Sex } \\
\hline Men & 6 & 12 \\
\hline Women & 43 & 88 \\
\hline \multicolumn{3}{|l|}{ Profession } \\
\hline - Households & 20 & 40.8 \\
\hline - $\quad$ Students & 3 & 6.1 \\
\hline - Informal sector & 2 & 24.5 \\
\hline - $\quad$ Civil servants & 14 & 28.6 \\
\hline \multicolumn{3}{|l|}{ Matrital status } \\
\hline - $\quad$ Married & 39 & 79.6 \\
\hline - Single & 5 & 10.2 \\
\hline - $\quad$ Others (widowed and divorced) & 5 & 10.2 \\
\hline \multicolumn{3}{|l|}{ Provenance } \\
\hline - $\quad$ Conakry & 31 & 63.3 \\
\hline - Country side & 18 & 36.7 \\
\hline
\end{tabular}


Table 2. Distribution of hypothyroidy symptoms.

\begin{tabular}{lcc}
\hline \multicolumn{1}{c}{ Symptoms } & $\begin{array}{c}\text { Number } \\
(\mathbf{n}=49)\end{array}$ & $\begin{array}{c}\text { Percentage } \\
(\%)\end{array}$ \\
\hline Hypo metabolic & & \\
- $\quad$ Constipation & 22 & 48.89 \\
- $\quad$ Chilliness & 15 & 30.61 \\
- $\quad$ Physical asthenia & 21 & 42.85 \\
- $\quad$ Hair loss & 14 & 28.57 \\
Cutaneous and subcutaneous infiltration & & \\
- $\quad$ Weight gain & 15 & 30,61 \\
- $\quad$ Sickness of the voice & 10 & 20.40 \\
\hline
\end{tabular}

$20.40 \%$ ( 10 cases). In $55.55 \%$ of cases, the patients in our study had undergone total or subtotal thyroidectomy.

\section{Paraclinical characteristics}

Anterior cervical ultrasound was requested in all patients with a goiter. It showed a homogeneous goiter in $47.0 \%$ of cases and a multi nodular goiter in $29.4 \%$ of cases. TIRADS score 3 and 1 was the most represented, i.e., $28.6 \%$ of cases, followed by score 2 and 4 in $21.4 \%$ of cases.

Thyroid assessment was performed in all cases and the mean thyroid hormone levels were as follows: TSH at $24.56 \pm 14.1 \mathrm{mU} / \mathrm{ml}, \mathrm{FT} 4$ at $10.97 \pm 3.4$ $\mathrm{pmol} / \mathrm{l}$ and FT3 at $1.51 \pm 1.5 \mathrm{pmol} / \mathrm{l}$.

Anti-TPO antibodies were measured in $67.74 \%$ of patients and were positive in $19.4 \%$ with a mean level of $450.72 \mathrm{ng} / \mathrm{l}$, anti-TG antibodies were measured in $76.5 \%$ and were positive in $17.7 \%$ of cases with a mean level of $440.58 \mathrm{ng} / \mathrm{l}$.

The cost of the hormonal assessment (TSHus, FT4 and FT3) was one million Guinean francs (approximately 110 USD), which is equivalent to twice the minimum wage in Guinea [5].

On the etiological level (see Table 3)

The etiologies of hypothyroidism ( 49 cases) were thyroidectomy in 21 patients (42.9\%), Hashimoto's thyroiditis in $34.7 \%$. Iatrogenic hypothyroidism by synthetic antithyroid in 4 cases and by radioactive iodine therapy in 03 cases. Central hypothyroidism as part of panhypopituitarism was noted in one patient. A case of congenital hypothyroidism was observed in a 2-year-old child patient.

\section{On the therapeutic level}

The majority of patients (85.8\%) were under a life-long replacement therapy, it was L-thyroxine in all cases of proven hypothyroidism with an average dose of 82.93 micrograms per day, monitoring was observed in $12.3 \%$ of cases. Euthyroidism was obtained after an average of 6 months. None of these patients had any treatment-related adverse events.

The high number of lost to follow-up (38.8\%) and the high cost of the work-up were the main challenges in our study. 
Table 3. Distribution of hypothyroidy etiologies.

\begin{tabular}{ccc}
\hline Etiologies of hypothyroidy & $\begin{array}{c}\text { Number } \\
(\mathbf{n}=\mathbf{4 9})\end{array}$ & $\begin{array}{c}\text { Proportion } \\
(\%)\end{array}$ \\
\hline Post thyroidectomy & 21 & 42.9 \\
Thyroiditis & 17 & 34.7 \\
Synthetic antithyroid drugs & 4 & 8.2 \\
Radioactive iodine & 3 & 6.2 \\
Endemic goiter & 2 & 4.0 \\
Congenital & 1 & 2.0 \\
Centrale & 1 & 2.0 \\
Total & 49 & 100 \\
\hline
\end{tabular}

\section{Discussion}

This study reflects hospital data on hypothyroidism in Guinea. Of the 290 patients who consulted for thyroid pathology, 49 patients were diagnosed with hypothyroidism, i.e., a frequency of $14 \%$. This rate is similar to the $18.3 \%$ reported by Brah S et al. [2] in Niger in a study of dysthyroidism, but significantly lower than that of Mahamane S et al. [3] who reported a frequency of $32.3 \%$. This lower rate could be explained by the size of our sample, which was larger, and by the fact that TSH measurement was systematic in our study.

\section{Epidemiological characteristics}

The mean age of our patients was $48.65 \pm 19.93$ years with extremes ranging from 2 to 80 years. This rate is different from that of Mahamane S et al. [3] who reported a mean age of $40.1 \pm 9.1$ years with extremes of 20 and 90 years. The female sex was predominant in our series, i.e., $88 \%$ with a sex ratio of 0.13 .

This result is close to that of Dramé B et al. in Bamako and Nadjia B et al. in Algeria who found respectively a sex ratio M/F of 0.11 and 0.16 [6] [7]. This female predominance could be explained by the fact that thyroid pathology is commonly found among young adult women compared to men [4].

Housewives were the most affected socio-professional category (40.81\%). Our result is lower than that reported in the Niger series by Mahamane $\mathrm{S}$ et al. [3] and Yacouba B et al. [8] who also found a high tendency among housewives with a frequency of $64.8 \%$ and $64 \%$ respectively. This could probably be explained by the fact that the schooling rate of women is still low in our context and by the fact that they are often subject to permanent stress in connection with the overload of work in the household. However, we do not yet have data that establish a correlation between hypothyroidism and housewives, but these results nevertheless show a high frequency within this socio-professional category.

In our study, $63.27 \%$ (31 cases) of the patients resided in Conakry against $36.73 \%$ (18 cases) outside Conakry. This could be explained on the one hand by the choice of the urban site of the study, and on the other hand by the fact that 
patients living in the interior of the country do not often have access to specialized care.

\section{Clinical characteristics}

The average duration of the evolution of symptoms was 3.64 years. The insidious and nonspecific nature of the signs of hypothyroidism, the inaccessibility of the population to care and the lack of training of health professionals on the disease would explain this long delay in diagnosis.

In our study, the hypo-metabolism syndrome was in the foreground and manifested itself by constipation in $44.89 \%$ (22 cases), physical asthenia in $46.67 \%$ (21 cases), and chilliness in 30.61\% (15 cases). Similar results have been reported in other studies. Thus, in Niger, Mahamane S et al. [3] noted the hypo-metabolic syndrome in the foreground, represented by asthenia and constipation; and Brah $S$ et al. [2] noted the hypo-metabolic syndrome in the foreground with constipation, physical asthenia and bradycardia.

The syndrome of cutaneous and subcutaneous infiltration was manifested mainly by weight gain in $30.61 \%$ (15 cases), hoarseness of voice in $20.40 \%$ (10 cases).

\section{Paraclinical characteristics}

Anterior cervical ultrasound was performed in all cases of goiter and it showed a homogeneous goiter in $47 \%$ of cases and a multi nodular goiter in $29.41 \%$ cases. TIRADS score 3 was the most represented, i.e., $35.29 \%$ followed by score 1 , i.e., $29.41 \%$.

TSHus was high in all cases with a mean level of $24.56 \pm 14.4 \mu \mathrm{U} / \mathrm{l}$. Our result is close to that of Mahamane S et al. [3] who reported a mean TSHus level of $30.3 \pm 20 \mu \mathrm{U} / \mathrm{l}$ but significantly lower than that of Sidibé E. H. et al. [9] in Dakar who reported a TSHus level of $63.7 \pm 51 \mu \mathrm{U} / 1$

Anti-TPO antibodies were measured in $67.74 \%$ of patients and were positive in $19.4 \%$ with a mean level of $45 \pm 0.72$; anti-TG antibodies were measured in $76.5 \%$ and were positive in $17.7 \%$ of cases with a mean level of $44 \pm 0.58$.

In our study, arterial hypertension $(\mathrm{AH})$ was the most frequent associated pathology, i.e., $57.14 \%$ of cases, followed by type 2 diabetes (T2DM), i.e., $42.85 \%$. More than half of our patients had a history of thyroidectomy (55.55\%). Among them, 21 (84\%) had performed a subtotal thyroidectomy and $4(16 \%)$ had performed a total thyroidectomy. This result is lower than the $72.4 \%$ of Abodo J et al. [10] but still confirms the high frequency of surgery in our region.

This high frequency of thyroidectomy could be explained by the fact that thyroid surgery is more practiced in our context because of the insufficiency of the technical platform.

\section{Etiological aspect}

The main causes of hypothyroidism were thyroidectomy in 21 cases (42.85\%), followed by thyroiditis (15 cases of Hashimoto disease, 1 case of De Quervain's thyroiditis, and 1 case of postpartum thyroiditis) in 17 cases (34.69\%); 4 cases $(8.16 \%)$ of post synthetic antithyroidism hypothyroidism, 3 cases of post-irradiation 
hypothyroidism (6.12\%); 2 cases $(4.08 \%)$ of endemic goiter; 1 case of congenital hypothyroidism $(2.04 \%)$ and 1 case of central hypothyroidism (2.04\%), which is consistent with the rarity of this etiopathogenic entity.

Our result is similar to the $38.5 \%$ of Nadjia B et al. [7] in Algeria but lower than that of Niger [3] and Ivory Coast [10] where thyroidectomy was noted respectively in $51.9 \%$ and $72.4 \%$.

This high rate of surgery could explain the delay in consultation of the population, because the studies of Diédhiou and Melliere had shown that hypothyroidism was the most frequent complication of thyroid surgery and that it would be frequent after removal of a large goiter [11] [12].

\section{Therapeutic and evolutionary aspects}

Patients were under a life-long replacement therapy (i.e., L-thyroxine) in all cases of proven hypothyroidism (97.67\%), with an average dose of 82.93 micrograms per day. Euthyroidism was achieved after an average of 6 months. This relatively long delay could be explained by the challenges associated with monitoring, including regular thyroid hormone measurements to adjust replacement therapy.

None of these patients had any treatment-related adverse events.

All patients had a favorable clinical and biological outcome. However, 61.21\% of patients had irregular follow-up. This could reflect the lack of information of the patients on their pathology on the one hand and the high cost of the check-up on the other hand which must be done throughout the follow-up. This means that compliance with treatment is low and the number of patients lost to follow-up is high. The same observation has been made in other African series [13] [14].

It is to be noticed that the sample size, the high cost and the local unavailability of certain complementary investigations, notably immunology and anatomo-pathology, were the limitations found in this work. Therefore, the certainty of the etiological diagnosis could not be established in all cases. Moreover, the data cannot be extrapolated to the entire Guinean population.

\section{Conclusions}

Hypothyroidism is frequent at the University Hospital of Conakry with a clear predominance of women. Surgery remains the main cause in our context, followed by autoimmune causes.

The clinical evolution is favorable in all cases under treatment, but patient education remains a crucial step for successful treatment.

\section{Conflicts of Interest}

The authors declare no conflict of interest.

\section{References}

[1] Devdhar, M., Ousman, Y.H. and Burman, K.D. (2007) Hypothyroidism. Endocri- 
nology and Metabolism Clinics of North America, 36, 595-615. https://doi.org/10.1016/j.ecl.2007.04.008

[2] Brah, S., Mahamane Sani, M.A., Daou, M., Andia, A., Bade, M.A., Bakasso, R., et al. (2016) Les Dysthyroïdies dans le Service de Médecine Interne de l'Hôpital National de Niamey, Niger. Health Sciences and Disease, 17, 4.

[3] Mahamane, M.S. (2018) Étiologies des Hypothyroïdies de l'Adulte à l'Hôpital National de Niamey (Niger). Health Sciences and Disease, 19, 1.

[4] Kaké, A., Diallo, M.M., Sylla, D., Diallo, A.M., Camara, I., Keita, A., et al. (2019) Thyroid Disease at the University Hospital of Conakry, Guinea. Open Journal of Internal Medicine, 9, 105-111. https://doi.org/10.4236/ojim.2019.94015

[5] Central Intelligence Agency (US) (2021) Africa: Guinea-The World FacebookCentral Intelligence Agency [Internet].

[6] Dramé, B. (2015) Aspects cliniques et étiologiques de l'hypothyrö̈die dans le service de médecine et d'endocrinologie de l'hôpital de Bamako. Annales d'Endocrinologie, 76, 418. https://doi.org/10.1016/j.ando.2015.07.380

[7] Nadjia, B., Zakaria, B. and El Amine, A.M. (2012) Aspects étiologiques des hypothyroïdies périphériques de l'adulte: à propos de 65 cas. Diabetes \& Metabolism, 38, A118-A119. https://doi.org/10.1016/S1262-3636(12)71476-3

[8] Yacouba, B. (2013) Les dysthyroïdies: Aspects épidémiologiques, diagnostics, thérapeutiques et évolutifs à propos de 60 cas observés à l'HNN. Réseau Bibliothèques $d u$ Niger, 168, 32.

[9] Sidibé, E.H. (1997) Caractéristiques cliniques de l'hypothyroïdie primaire à Dakar à propos de 37 observations, cahiers santé. Cahiers d’études et de recherches francophones/Santé, 7, 291.

[10] Abodo, J., Yao, A., Koffi-Dago, P., Hué, A., Danho, J., Ahoussi, J.B., et al. (2019) Caractéristiques des Thyropathies en Côte d'Ivoire. Health Sciences and Disease, 20, 32-35.

[11] Diédhiou, D., Thioye, M.M., Sow, D., Ndour, M.A., Diallo, I.M., Halim, C., et al. (2021) Thyroïdectomie au Centre Hospitalier Abass Ndao: Profils cliniques, indications et résultats à propos de 706 cas. RAFMI, 28, 37-43.

[12] Melliere, D., Etienne, G. and Mahmoud, M. (1990) Nodules thyroïdiens hypofixants cliniquement banals, quelles indications? A propos de 2678 nodules froids opérés. La Semaine des hôpitaux de Paris, 66, 1329-1334.

[13] Baldé, M.M., Baldé, M.D., Kaké, A., Diallo, M.M., Camara, A. and Bah, D. (2007) Hyperthyroïdie à Conakry: Particularités cliniques et thérapeutiques. Annales de P Université Marien Ngouabi, 8, 23-27.

[14] Akossou, S.Y., Napporn, A.A., Hillah, A., Sokpoh-Diallo, K. and Amedegnato, M.D. (2000) Les difficultés de la prise en charge des thyréotoxicoses en Afrique Noire: l'expérience du Togo. Louvain Médical, 119, 314-316. 